\title{
(ब) $\triangle \Theta \odot$ Divisão do trabalho e apologia da ordem em Thomas Hobbes e Norbert Elias
}

\author{
Anderson Alves Esteves*
}

Resumo: O artigo expõe os juízos afirmativos granjeados por Thomas Hobbes e Norbert Elias a respeito da divisão do trabalho e de suas relações com a ordem social, a despeito das diferenças de métodos e de métricas dos autores em pauta. De Thomas Hobbes, recolhe-se a demonstração, com subjacência no raciocínio hipotético-dedutivo do filósofo inglês, de que, do indivíduo, palmilha-se à sociedade, do contrato que edifica o Estado, envereda-se à divisão do trabalho como uma das maneiras de estatuir o conforto necessário à manutenção da sociedade civil. De Norbert Elias, apanha-se a relação processual entre sociogênese e psicogênese que, sem opor indivíduo e sociedade, trata da formação da divisão do trabalho e da individualidade como fenômenos inseparáveis e peculiares ao processo civilizador.

Palavras-chave: Divisão do trabalho. Ordem social. Thomas Hobbes. Norbert Elias.

Division of work and apology of the order in thomas hobbes and norbert elias

Abstract: The article exposes the assertive judgments made by Thomas Hobbes and Norbert Elias concerning the division of labor and its relations with the social

\footnotetext{
* Doutor em Filosofia pela Pontifícia Universidade Católica de São Paulo (PUC-SP). Pósdoutorando em Sociologia pela Universidade de São Paulo. Professor do Instituto Federal de São Paulo (IFSP). E-mail: andersonesteves@ifsp.edu.br ORCID: https://orcid.org/0000-0003-1479-3323
} 
order, despite the differences of methods and metrics of the authors in question. From Thomas Hobbes, the demonstration, based on the hypothetical-deductive reasoning of the English philosopher, is gathered from the demonstration that, from the individual, ingrained in society, from the contract that builds the State, the division of labor is divided as one of the ways of establishing the comfort necessary for the maintenance of civil society. From Norbert Elias, one picks up the procedural relation between sociogenesis and psychogenesis that, without opposing individual and society, deals with the formation of the division of labor and individuality as inseparable phenomena peculiar to the civilizing process.

Key-words: Division of labor. Social order. Thomas Hobbes. Norbert Elias.

\section{División del trabajo y apología del orden en thomas hobbes y norbert elias}

Resumen: El artículo expone los juicios afirmativos desmenuzados por Thomas Hobbes y Norbert Elias acerca de la división del trabajo y de sus relaciones con el orden social, a pesar de las diferencias de métodos y de métricas de los autores en pauta. De Thomas Hobbes, se recoge la demostración, con subyacencia en el razonamiento hipotético-deductivo del filósofo inglés, de que, del individuo, se adapta a la sociedad, del contrato que edifica el Estado, se entra en la división del trabajo como una de las formas de estatuir el confort necesario para el mantenimiento de la sociedad civil. De Norbert Elias, se recoge la relación procesal entre sociogénesis y psicogénesis que, sin oponer individuo y sociedad, trata de la formación de la división del trabajo y de la individualidad como fenómenos inseparables y peculiares al proceso civilizador.

Palabras clave: División del trabajo. Orden social. Thomas Hobbes. Norbert Elias 
Sem encetar uma teoria a se preocupar, antes de tudo, com a divisão do trabalho, a obra de Thomas Hobbes já denotava, ao início da reflexão moderna, durante o século XVII, a necessidade de tratar do tema. Na perspectiva do raciocínio hipotético-dedutivo do Autor, à medida que o objeto estava elencado como um dos elementos resultantes da edificação da sociedade civil e imprescindível à aquisição do conforto a manter a ordem social, a divisão do trabalho apareceu como uma das instituições decorrentes do contrato que fundou o Leviatã e garantiu segurança a todos. De sua parte, Norbert Elias, durante o século XX, escreveu quando a divisão do trabalho estava estatuída como tema tradicional das Ciências Sociais e da Filosofia, mas não apenas replicando os escritos de outros pensadores, uma vez que, ao propor chaves de explicação a pensarem sociedade e indivíduo sem que fossem independente um do outro e ao pesquisar a divisão do trabalho como expoente e veículo das transformações que caracterizaram a Modernidade, tratou da questão com o que o sociólogo denominou Sociologia de processos. O alvitre deste artigo propõe que, a despeito das diferenças metodológicas entre os autores, a apologia da ordem social estabelecida foi um denominador comum a aproximar as duas produções teóricas e sugere, ao final, dois pontos de contato entre elas.

O raciocínio hipotético-dedutivo de Hobbes, exercido à maneira geométrica, parte de um axioma, a saber, o direito natural constitutivo ao indivíduo, para dele inferir condições pacíficas de vínculos societários: dos sujeitos contratuais livres e apriorísticos a raciocinarem/calcularem - a 
razão, ela mesma, é tomada como "cálculo" (HOBBES, 1974, p. 31, grifo do Autor) e "computação" (Hobbes, 2012, p. 19, grifo do Autor) à medida que soma ou subtrai uma sequência de nomes à totalidade discursiva soluções aos problemas do estado de natureza, arvoram-se, mediante “especulação e dedução" (HOBBES, 1974, p. 129), o Estado-Leviatã como instituição que garante a segurança para todos e, consequentemente, a sociedade civil. O homem, aquele que brota da natureza como “cogumelos" (HOBBES, 1992, p. 158), racional, maduro, livre, é o ponto de partida; o contrato, a sociedade, o Estado, os pontos de chegada. Assim, o filósofo inglês pensa evitar controvérsias em virtude do esprit de géometrie (1) comparar "figuras em movimento" (HOBBES, 2002, p. 17) em lugar de fundamentar-se no "discurso habitual da língua" do qual o "erro" (HOBBES, 2002, p. 89) resulta; (2) tornar o pensamento autônomo em relação à experiência e à observação, em regra, originários de juízos errôneos; (3) operar de acordo com a metáfora do relógio [vincada por um cartesianismo (TAYLOR, 2011, p. 256), mas além do método de análise/resolutivo, também o de síntese/compositivo (HOBBES, 2012, p. 76), uma vez que a citada metáfora pode partir das causas para encontrar efeitos ou destes para aquelas, decompor ou reconstituir elementos, operar por adição ou subtração (BOBBIO, 1991, p. 76)], exposta em Do cidadão, e entender as engrenagens desmontando o mecanismo a fim de apreender o funcionamento de cada peça - da mesma forma, no governo civil, descobrir a qualidade da natureza humana para estabelecer, em seguida, os alicerces do Estado como máquina criada pelo engenho humano [em Elementos de filosofia, o Autor deixou claro que Do cidadão foi uma aplicação das descobertas em Filosofia Natural - notadamente as de 
Copérnico, de Galileu e dos médicos - à Filosofia Civil (HOBBES, 2012, p. 06)]. O pensamento guia-se por "inferência evidente e necessária" (HOBBES, 1992, p. 120) e conduz a análise extraindo consequências do princípio anteriormente exposto - mesmo o emprego da retórica, como Skinner observa existir em Leviatã, e até a continuidade de temas, que Hobbes havia tratado na etapa mais juvenil de sua produção (quando ainda não estava filiado ao método matemático) e extensiva a seus escritos ulteriores, como interpreta Leo Strauss, não rechaçam a exposição dedutiva observada nos livros escritos a partir de 1640, não impedem a qualificação da Ciência Política hobbesiana como engenharia social (BLOCH, 2006, p. 135) e não se eximem de transparecer que a concepção do Autor está investida de um individualismo radical (RIBEIRO, 1999, p. 114), uma vez que a natureza do indivíduo (suas faculdades corporais e cognitivas) subjaz a construção teórica - da Física à Filosofia moral e civil, como o filósofo anuncia em Elementos de filosofia (Hobbes, 2012, p. 81).

$\mathrm{O}$ individualismo radical de Hobbes se expressa também nas ideias contrárias à hipótese aristotélica do zoon politikon: para o pensador moderno, as pessoas reúnem-se na expectativa de "granjearem algum benefício" [HOBBES, 1992, p. 31] (lucro, ofício, prazer) e na de que os "homens não se deleitam tanto com a sociedade, mas com sua própria vã glória” (HOBBES, 1992, p. 30) - preocupar-se consigo mesmo não é um vício [formulação a ser aproveitada por Adam Smith, posteriormente (ESTEVES, 2018, p. 153)] à medida que fazer algo bom para si significa estar de acordo com a natureza racional. Suplementando a questão, (1) os indivíduos não encontram termo para seus desejos e querem gozar continuamente, vivem em "um perpétuo e irrequieto desejo de poder e 
mais poder" [HOBBES, 1974, p. 64] (além de também pretenderem segurança, honra, riqueza, reputação); com efeito, ganham inimizades de seus concorrentes e pensam em repeli-los, em suplantá-los e em matá-los ${ }^{1}$. Para o Autor, (2) os homens, a despeito de terem diferentes paixões, são iguais em matéria de faculdades corporais, espirituais e esperançosos em atingir seus fins, todos podem "reclamar qualquer benefício a que outro não possa também aspirar" (HOBBES, 1974, p. 78), disputam os alvos de seus anseios, antecipam ações na expectativa de adquiri-los e conservá-los, desconfiam dos outros indivíduos e lançam mão de toda sorte de artifícios para vencerem; assim, enseja-se uma "guerra de todos contra todos" (HOBBES, 1992, p. 38), uma vez que a lei de natureza (jus naturale) ${ }^{2}$ e o direito de natureza (lex naturalis) ${ }^{3}$ a outorgam, que todos têm direito a tudo e a mesma sagacidade. Trata-se, portanto, de uma guerra justa, “racional" (RIBEIRO, 1989, p. 55) à medida que é correlata ao estado de natureza isento de um poder comum que discirna o que é o bom e o mau "o estado dos homens em sua liberdade natural é o estado de guerra" (HOBBES, 2002, p. 96) no qual cada um busca o bem para si mesmo. Contudo, adverte-se que a situação não é decorrente de uma mera

${ }^{1}$ Contudo, Hobbes elenca desejos que inclinam à obediência a um poder comum: conforto, deleite sensual, conhecimento, artes da paz e ócio predispõem-se à obediência, "pois com tais desejos se abandona a proteção que poderia esperar-se do esforço e trabalho próprios" (HOBBES, 1974, p. 65).

2 "Liberdade que cada um possui de usar seu próprio poder, da maneira que quiser, para a preservação da sua própria natureza, ou seja, de sua vida; e consequentemente de fazer tudo aquilo que seu próprio julgamento e razão lhe indiquem como meios adequados a esse fim" (HOBBES, 1974, p. 82).

3 "Preceito ou regra geral, estabelecido pela razão, mediante o qual se proíbe a um homem fazer tudo o que possa destruir sua vida ou privá-lo dos meios necessários para preservá-la" (HOBBES, 1974, p. 82). 
“antropologia negativa" (LIMONGI, 2012, p. 63), ela está inserida em um contexto competitivo, de desconfiança recíproca, de busca de determinados fins e de obsolescência da igualdade natural de outrora, uma vez que cada um instrumentaliza suas capacidades para majorar o próprio poder e se acautelar em relação aos demais; portanto, a guerra de todos contra todos pode ser interrompida à medida que os costumes são relevantes para a questão e que mostravam existir um quê de "social" (LIMONGI, 2016, p. 159) ou uma "semi-socialidade" (RIBEIRO, 1992, p. XXVIII): as primeiras linhas de Do cidadão e de o Leviatã deixam claro que se, de um lado, o homem pode ser um "lobo", de outro, pode ser um “deus" (HOBBES, 1992, p. 04) para si, que ele não é apenas "matéria", mas "artífice" (HOBBES, 1974, p. 09, grifo do Autor) da cidade em que vive e, destarte, pode construir modos de vida pacíficos - Hobbes, dessa forma, descortinou a política como atividade secularizada que lida com a lei de natureza na Modernidade em florescimento (IANNI, 2004, p. 15). E não apenas descortinou, mas produziu ideologia à medida que projetou, na natureza humana, o ambiente inglês de desenvolvimento da manufatura, do comércio marítimo, da colonização, de "relação monetária" e de "regateio" (MARX; ENGELS, 2007, p. 395).

Com efeito, para se conservarem, os indivíduos-cogumelo elaboraram e firmaram um "contrato" (HOBBES, 1974, p. 84) com a estratégia de duas vias (não opostas) de suspensão da guerra de todos contra todos. Em uma, frustraram a igualdade (que também era a igualdade de se matarem, de roubarem uns aos outros e de prolongar a guerra indefinidamente) e substituíram-na pela diferenciação e pela desigualdade, inventando regras (leis) a submeterem a todos, a protegerem-se em relação 
aos demais e a renunciarem e transferirem seu antigo direito a tudo tratam-se daquelas leis expostas por Hobbes em o Leviatã, no Capítulo III de Do cidadão e nos capítulos XV a XVIII de Os elementos da lei natural e política. O filósofo inglês denominou-as de leis de natureza e as qualificou como naturais, racionais, morais e divinas ${ }^{4}:$ de modo geral, elas inclinam os indivíduos a abrirem mão do direito a todas as coisas, a promoverem uma sociabilidade em respeito a esta norma e a evitarem o reinício da guerra de todos contra todos - a prescrição "Faz aos outros o que gostarias que te fizessem a ti" (HOBBES, 1974, p. 97, grifo do Autor) as resume e a Filosofia moral, a ciência que se ocupa do que é o bom e o mau para a conservação das sociedades humanas, as estuda ${ }^{5}$. Porém, o Autor deixa claro que, se as leis de natureza não forem profícuas para findarem a guerra de todos contra todos, as ações que fazem valer o direito

\footnotetext{
4 "São chamadas leis de natureza, por serem ditadas da razão natural, e também leis morais, porque dizem respeito às maneiras e à conveniência dos homens uns com os outros. Da mesma forma, elas são também leis divinas, em consideração ao autor daquelas, Deus Todo-Poderoso; e devem portanto concordar ou, pelo menos, não repugnar a palavra de Deus revelada na Santa Escritura” (HOBBES, 2002, p. 121).

5 “O bem e o mal são nomes que significam nossos apetites e aversões, os quais são diferentes conforme os diferentes temperamentos, costumes e doutrinas dos homens. E homens diversos não divergem apenas, em seu julgamento, quanto às sensações do que é agradável ou desagradável ao gosto, ao olfato, ao ouvido, ao tato e à vista, divergem também quanto ao que é conforme ou desagradável à razão, nas ações da vida cotidiana. Mais, o mesmo homem, em momentos diferentes, diverge de si mesmo, às vezes louvando, isto é, chamando bom, àquilo mesmo que outras vezes despreza e a que chama mau. Daqui procedem disputas, controvérsias, e finalmente a guerra. Portanto enquanto os homens se encontram na condição de simples natureza (que é uma condição de guerra) o apetite pessoal é a medida do bem e do mal. Por conseguinte todos os homens concordam que a paz é uma boa coisa, e portanto que também são bons o caminho ou meios da paz, os quais (...) são a justiça, a gratidão, a modéstia, a equidade, a misericórdia e as restantes leis de natureza; quer dizer, as virtudes morais; e que seus vícios contrários são maus. Ora a ciência da virtude e do vício é a filosofia moral, portanto a verdadeira doutrina das leis de natureza é a verdadeira filosofia moral" (HOBBES, 1974, pp. 98-99, grifo do Autor).
} 
de natureza continuam legítimas. Adiciona-se à advertência o problema das leis de natureza, por si mesmas, não evitarem a guerra de todos contra todos: como as vontades dos homens não são voluntárias e como eles estão inclinados a agirem de acordo consigo mesmos, a violação às regras são frequentes, por isso, os desejos precisam ser submetidos a algo, alguém ou alguns que palmilhem na direção da defesa comum, na conformação "à unidade e à concórdia" (HOBBES, 1992, p. 109), na inclinação a observarem as leis de natureza e a conterem-se, na transformação dos homens naturais em cidadãos.

Por isso, a segunda via é tão importante quanto a primeira: a renúncia ao gládio individual conta com a edificação - efetivada por pessoas que desejaram contratar a troca de obediência por segurança - de um Deus mortal, um homem artificial, um Leviatã que reine sobre os orgulhos e as vaidades (RIBEIRO, 2001, p. 09) de todos. O cálculo que os indivíduos-cogumelo fizeram, a partir da racionalidade a eles constituinte, e a vontade de preferirem a vida e a paz em detrimento da guerra, legitimaram a formação e um "poder capaz de manter todos em respeito" (HOBBES, 1974, p. 79) e de submetê-los à sociabilidade comum e expressam o "atomismo político" (TAYLOR, 2011, p. 114) que caracteriza a teoria hobbesiana. O Estado-Leviatã coage contra as infrações e pune aqueles que desrespeitarem as leis estatuídas pelos próprios contratantes: o $m e d o^{6}$ da pena inibe o rompimento do pacto e outra paixão, a esperança,

\footnotetext{
${ }^{6}$ Em Do cidadão, Hobbes considera que "é inútil impor qualquer proibição aos homens, se ao mesmo tempo não se induz neles um medo ao castigo" (HOBBES, 1992, p. 244); em Leviatã, que "de todas as paixões, a que menos faz os homens tender a violar as leis é o medo. Mais: excetuando algumas naturezas generosas, é a única coisa que leva os homens a
} 
auxilia o Estado à medida que os indivíduos percebem esta instituição como garantidora de uma ordem que contribua para o respeito mútuo ao contrato a fim de, assim, alcançar-se não apenas a segurança e a paz, mas o progresso e o conforto. Para a efetividade da coerção sobre as paixões naturais que conduzem à parcialidade, o Estado precisa ser suficientemente forte para vencer, julgar e punir os interesses e apetites particulares em nome do "bem comum" (HOBBES, 1974, p. 109) da lei (vontade e apetite do Estado), para impedir a "liberdade absoluta" (HOBBES, 1992, p. 263) peculiar ao estado de natureza e promover a liberdade própria ao estado civil, que optou pela autoridade das "leis civis" (HOBBES, 1974, p. 134, grifo do Autor) com o objetivo de garantir conservação aos indivíduosartífice destas mesmas leis e do próprio Estado, uma forma de liberdade a estabelecer a "mútua relação entre proteção e obediência" (HOBBES, 1974, p. 414), investir na ação voluntária de jogar objetos ao mar para que o barco não afunde [imagem que circulava na emblemata inglesa durante $o$ século XVII (SKINNER, 2010, p. 40)] e continuar a permitir ao súdito a possibilidade de lutar pela preservação da própria vida caso o soberano não mais possa assegurá-la (RIBEIRO, 1989, p. 68) - a socialização somente fez sentido ao preservar a vida e, se esta for ameaçada, a defesa que cada um faz de si está legitimada. Além de forte, o poder do Estado precisa ser soberano, "absoluto" (HOBBES, 1992, p. 123), operar como um "grande Leviatâa $^{\text {"7 }}$, que observa e assegura tudo o que foi estabelecido pelo

respeitá-las quando a violação das leis não parece poder dar lucro ou prazer" (HOBBES, 1974, p. 183).

7 "É esta a geração daquele grande Leviatã, ou antes (para falar em termos mais reverentes) daquele Deus Mortal, ao qual devemos, abaixo do Deus Imortal, nossa paz e defesa. Pois 
contrato, ao mesmo tempo em que é anterior e se mantém acima das leis e com poder para alterá-las, proteger a todos dos estrangeiros e de si mesmos, monopolizar o julgamento do que é o bem e o mal, a arrecadação de impostos, derrotar todas as formas de sedições e faccionismos entre os súditos e que os tornam vulneráveis ao retorno da guerra de todos contra todos (HOBBES, 2001, p. 32).

Eis o poder soberano do Estado da era mercantilista: além de proteger contra a concorrência estrangeira, ele está compassado com o "germinante interesse empresarial" (BLOCH, 2006, p. 96), caracterizado como "condição de possibilidade" [RIBEIRO, 2003, p. 17] (precede, fixa) ao avanço da divisão do trabalho, aos bens privados (o meum e o tuum e a segurança de que a propriedade não será atacada), às comodidades, à paz, ao avanço do comércio e da troca - o capítulo XXIV de o Leviatã transparece o entrelaçamento entre a perspectiva hobbesiana do direito natural e o interesse dos proprietários e do Estado mercantilista ${ }^{8}$ e a própria maneira de pensar revela-se burguesa, uma vez que o contrato, o

graças a esta autoridade que lhe é dada por cada indivíduo no Estado, é-lhe conferido o uso de tamanho poder e força que o terror assim inspirado o torna capaz de conformar as vontades de todos eles, no sentido da paz e em seu próprio país, e da ajuda mútua contra os inimigos estrangeiros. É nele que consiste a essência do Estado, a qual pode ser assim definida: Uma pessoa de cujos atos uma grande multidão, mediante pactos recíprocos uns contra os outros, foi instituída por cada um como autora, de modo a ela poder usar a força e os recursos de todos, da maneira que considerar conveniente, para assegurar a paz e a defesa comum" (HOBBES, 1974, pp. 109-110, grifo do Autor).

${ }^{8}$ Contudo, é um exagero reduzir o pensamento hobbesiano à expressão dos interesses da burguesia florescente: a propriedade continua subordinada ao Estado e, consequentemente, vive ameaçada à medida que o soberano pode requerê-la em nome do "bem comum do povo" (HOBBES, 2015, pp. 152-153); o Leviatã se atenta não apenas à propriedade, mas a interesses que não são genuinamente burgueses, como a vida e a honra; a obediência está subordinada à garantia da preservação da vida. 
individualismo e a idealização das características do indivíduo-cogumelo permitem pensar a arquitetura do Estado com subjacência não mais em famílias e nas relações entre servos e senhores (BOBBIO, 1991, p. 11). Sem o Estado:

- Não há lugar para a indústria, pois seu fruto é incerto; consequentemente não há cultivo da terra, nem navegação, nem uso das mercadorias que podem ser importadas pelo mar; não há construções confortáveis, nem instrumentos para mover e remover as coisas que precisam de grande força; não há conhecimento da face da Terra, nem cômputo do tempo, nem artes, nem letras; não há sociedade; e o que é pior do que tudo, um constante temor e perigo de morte violenta. E a vida do homem é solitária, pobre, sórdida, embrutecida e curta (HOBBES, 1974, p. 80).

- Antes da constituição do poder soberano (...) todos os homens tinham direito a todas as coisas, o que necessariamente provocava a guerra. Portanto esta propriedade, dado que é necessária à paz e depende do poder soberano, é um ato desse poder, tendo em vida a paz pública. Essas regras da propriedade (ou meum e tuum), tal como o bom e o mau, o legítimo e o ilegítimo nas ações dos súditos, são leis civis (HOBBES, 1974, p. 114, grifo do Autor).

Portanto, percebe-se como Hobbes projeta sobre sua teoria o ambiente belicoso da concorrência e do mercantilismo peculiar ao início do capitalismo, no qual a divisão do trabalho e a propriedade necessitavam de um Estado-Leviatã que regulasse a vida dos indivíduos-cogumelo de maneira a evitar a guerra de todos contra todos e a sustentar a esperança na aquisição e na manutenção da posse dos bens. Em Hobbes, a política é o âmbito da vida social que sobrepuja os demais: sem ela - sem contrato, 
leis civis e poder soberano - "o meum e o tuum não encontram lugar" (HOBBES, 2002, p. 135) e, consequentemente, retorna-se à guerra. Pintase o mundo de cabeça para baixo à medida que as condições sob as quais as pessoas vivem são apresentadas como decorrentes unilateralmente de suas vontades e estas fossem anteriores e/ou independentes do "modo de produção", do "intercâmbio", da "divisão do trabalho", da "propriedade privada" (MARX; ENGELS, 2007, p. 317).

Norbert Elias argumentou de forma a jamais separar as estruturas sociogenéticas (maiores divisão do trabalho e de funções, diferenciação e interdependência; resolução de concorrência e conflitos por vias que não a da força, formação de Estado centralizado e monopolizador da violência e da arrecadação de impostos) e psicogenéticas [autocontrole de impulsos com "automatismo" (ELIAS, 1993, p. 196) compulsivo] para expor o "processo civilizador" (ELIAS, 2011, p. 69) constituinte ao Ocidente Moderno: da antiga elite de cavaleiros medievais (cortesia) ao início da Modernidade (civilidade) e à sociedade burguesa dos séculos subsequentes (civilização), o Autor percebeu uma marcha no sentido da civilização dos costumes que freou a antiga imoderação das condutas, uma vez que os indivíduos das duas últimas sociedades caracterizadas como grandes unidades de sobrevivência, com órgãos centrais de comando que derrotaram a fragmentação política e o gládio individual, e com considerável aumento da divisão do trabalho e da interdependência, aprenderam a se autorregular e a interiorizar as coerções externas nas novas configurações sociais. 
A estratégia do Autor foi expor a constituição do processo civilizador ao "longo prazo" (ELIAS, 2011, p. 207) em que ocorreu e abordá-lo a partir de uma "sociologia realista" (ELIAS, 2001a, p. 214) e/ou "sociologia de processos" (ELIAS, 1994, p. 142): as categorias sociogênese e psicogênese explicam as estruturas sociais modernas e a formação da civilidade perseguindo provas empíricas encontradiças em livros de boas maneiras que atestam a alteração das condutas e na formação dos estados nacionais que edificaram novas formas de controle há uma "rede" (ELIAS, 1994, p. 22) de interdependência entre as pessoas que compõem a sociedade como "configuração" (ELIAS, 2011, p. 240) ou "figuração" (ELIAS, 2006, p. 25). Na sociedade de corte, rei e camareiro estavam sob uma configuração que expressava interdependência entre os indivíduos; assim, separar sociedade, de um lado, e indivíduo, de outro, considerando-os como "substâncias distintas e estáveis" (ELIAS, 2001a, p. 45) não ajuda a entender a ligação entre os indivíduos e o tamanho das decisões - jamais absolutas - que tanto o rei como o camareiro podiam tomar. É pela relação entre eles e pela ordem oculta e não planejada ${ }^{9}$, na

\footnotetext{
9 "Cada um dos passantes, em algum lugar, em algum momento, tem uma função, uma propriedade ou trabalho específico, algum tipo de tarefa para os outros, ou uma função perdida, bens perdidos e um emprego perdido. (...) A ordem invisível dessa forma de vida em comum, que não pode ser diretamente percebida, oferece ao indivíduo uma gama mais ou menos restrita de funções e modos de comportamento possíveis. Por nascimento, ele está inserido num complexo funcional de estrutura bem definida; deve conformar-se a ele, moldar-se de acordo com ele e, talvez, desenvolver-se mais, com base nele. Até sua liberdade de escolha entre as funções preexistentes é bastante limitada" (ELIAS, 1994, p. 21).
} 
qual estão inseridos, que se pode elucidar as redes de interdependência. Em outras palavras, que se pensa corretamente na sociedade e no indivíduo, ou, em termos eliasianos, em sociedade de indivíduos - aquela não é abstração e não pode ser enquadrada pelo sociologismo [ao contrário da hipótese da sociedade como "sistema", "harmonia imanente" (ELIAS, 2001a, p. 155), com um "ideal do nós” (ELIAS; SCOTSON, 2000, p. 42) a se sobrepor e impedir a individualidade e a percepção da realidade em virtude do recrudescimento do carisma que um grupo/sociedade faz de si mesmo], este não é átomo e homo clausus (ao contrário do que supõe a megalomania da res cogitans cartesiana e a metáfora hobbesiana do indivíduo-cogumelo que pensam em um eu hierarquicamente superior ao corpo, à matéria e à história), ambos estão em contínua relação, processo, construção, reconstrução, articulação e desarticulação (WAIZBORT, 1999, p. 99 et seq.) sem que ocorra substancialização de uma ou das duas partes e hipóstase de uma em relação a outra. Com efeito, o acordo metodológico proposto por Elias não toma a vereda do esprit de géometrie que marcou a obra hobbesiana: sociogênese, psicogênese, processo, rede, configuração, relação são categorias que em nada estão eivadas daquele raciocínio hipotético-dedutivo a conduzir o pensamento de um axioma a corolários mediante nexos necessários e demonstráveis.

Na Idade Média, o apanágio da sociogênese estava marcado pela fragmentação política que alocava uma nobreza guerreira a prescindir da 
autoridade central (feudalização ${ }^{10}$ ), "relações de escambo" (ELIAS, 1993, p. 33) em lugar da economia monetária, a terra como principal forma de propriedade, ausência de um Estado centralizado, menor divisão do trabalho e a indistinção entre os poderes econômico, militar e político, todos concentrados no senhor de terras. A psicogênese da elite cavalheirosa estava caracterizada pela ausência de controle sobre as "conduta e paixões", pela solução dos problemas com o artifício da “espada", pela afeição com "livre e ilimitada expressão", por "explosões de violência", pelo abandono à "alegria do momento" - pouco ou nada existia nas estruturas social e de personalidade a compelir à "moderação" dos atos e à edificação da "autodisciplina" (ELIAS, 1993, p. 70).

$\mathrm{Na}$ sociedade de corte, havia uma sociogênese vincada pela centralização política [o destaque de Elias para a crescente monopolização estatal da violência denota a proximidade com a posição weberiana (HEINICH, 2001, p. 16) à medida que dá grande relevância a fatores transcendentes à ordem material] nas mãos de um rei ou senhor absoluto e envolto a uma corte: formaram-se novos intercâmbios entre classes sociais e maneiras de solução de problemas que não contavam com a violência física, a disputa pela atenção do chefe político e a consequente demanda por distinção em relação aos concorrentes. Os fatores que colaboraram para essa nova era da história do Ocidente foram aqueles que diminuíram o poder da nobreza cavalheirosa e majoraram o das novas classes burguesas,

\footnotetext{
10 “A desintegração da propriedade, a transferência da terra do controle do rei para as várias gradações da sociedade guerreira como um todo - e isto, e nada mais, é a "feudalização"” (ELIAS, 1993, p. 65).
} 
a despeito dos mesmos fatores também contribuírem para tornar um dos antigos senhores mais poderoso que os demais (reduzidos a senhores de segunda ou terceira classe), e permitir, outrossim, a monopolização de territórios: o crescimento da divisão do trabalho e das funções, a monetarização da economia, a mobilidade social ascendente e descendente, a expansão do potencial e das tecnologias de guerra, o intercâmbio entre regiões, as migrações, as novas formas de administração, de supervisão dos territórios monopolizados (burocráticas, perenes, com separação de funções, expressivas da maior interdependência entre governantes e governados e entre os diversos grupos e a autoridade central) e o contingente de funcionalismo administrativo. A psicogênese da sociedade de corte, ao aglomerar dominantes e dependentes - ambos de diferentes gradações - e ao agrupar indivíduos de discernentes origens sociais, não era idêntica à medieval à medida que não mais se resumia a senhores que impunham suas vontades infrenes a pessoas que não podiam resistir; na corte, os indivíduos aprenderam "uma tutela dos afetos, uma autodisciplina e um autocontrole, uma racionalidade distinta" (ELIAS, 1993, p. 18) que tornava semelhante o comportamento de cortesãos e de burgueses - decoro corporal, civilização da conduta, rigor do vestuário, transformação da consciência e da libido estavam relacionados à centralização e à edificação da "forma absolutista de governo" (ELIAS, 1993, p. 19), mostravam-se imprescindíveis ao contexto nos quais todos eram rivais e, ao mesmo tempo, aliavam-se na corte que não funcionaria sem uma "conduta civilizada" (ELIAS, 1993, p. 146). O “mecanismo 
régio" (ELIAS, 1993, p. 148) jogava com a tensão entre grupos para alcançar maior coesão política e arbitrar $\operatorname{conflitos}^{11}$ à medida que a corte contemplava senhores de grande e de pequeno prestígio, pessoas que recebiam moradia, roupa, alimentação, presença de escribas, de sacerdotes, de burgueses a fazerem negócios etc.: não mais a espada, mas a monotonia e a obediência a regras burocráticas, a moderação dos afetos e a polidez resolviam os conflitos e as pendências. Explicitava-se, de acordo com Elias, a progressão da divisão do trabalho e da interdependência entre os indivíduos com o desenvolvimento da civilidade, uma vez que se difundiu

\footnotetext{
11 "O que encontramos nas lutas do século XVI e também do XVII são, em termos gerais, 'corporações burguesas' que já se tornaram suficientemente ricas, numerosas, poderosas e conscientes de seu valor, a ponto de oporem uma feroz resistência às reivindicações de dominação e poder da nobreza. Todavia, elas não têm capacidade nem força suficiente para reivindicar a dominação para si mesmas. Por outro lado, o que encontramos é uma nobreza ainda forte o bastante para desafiar a camada burguesa ascendente e afirmar-se em relação a ela, mas já fraca demais, sobretudo do ponto de vida econômico, para conseguir sua dominação sobre a burguesia. $\mathrm{O}$ fator decisivo nessa situação é que as funções judiciárias e administrativas da época já não cabiam mais à nobreza, de modo que ricas e poderosas corporações, à frente do parlamento, deram origem a uma espécie de camada superior da burguesia. Assim, com sua base financeira reduzida, a nobreza precisava do rei para fazer face à pressão das camadas burguesas e à sua riqueza crescente; as corporações burguesas necessitavam do rei, que as protegia das ameaças, pretensões e, também dos privilégios unilaterais de uma nobreza ainda presa à tradição cavalheiresca. Uma figuração com tal equilíbrio de tensões, na qual as duas ordens preservavam um razoável equilíbrio (em todo caso nenhum dos grupos antagônicos conseguia manter durante muito tempo uma preponderância decisiva sobre o outro), dava ao rei legítimo, aparentemente distanciado de ambos os grupos, a chance de aparecer pacificador, trazendo para os adversários esgotados a tranquilidade ansiada por todos" (ELIAS, 2001a, pp. 178-179).
} 
entre as pessoas a coexistirem em estruturas sociais assimétricas e hierárquicas - tais como os hôtels em um castelo real nos quais cada uma delas estava concomitantemente próxima e distante (CHARTIER, 2001, p. 20) - a compulsão do espírito de previsão e de cálculo, a civilização das condutas, a autodisciplina, a intriga e a inveja como substitutivas da violência física, a metamorfose da libido, a psicologização, a racionalização, a necessidade de distinção, de prestígio e de status, as cerimônias, o refinamento, a produção de uma "segunda natureza" (ELIAS, 1993, p. 251) entre as pessoas, a dissimulação das paixões em nome dos negócios:

Os indivíduos assim oscilam entre a resistência à compulsão à qual estão submetidos, o ódio à dependência em que vivem e à falta de liberdade, a nostalgia da livre rivalidade entre cavaleiros, por um lado, e o orgulho pelo autocontrole que adquiriram ou a satisfação ante as novas possibilidades de prazer de que desfrutam, por outro. Em suma, um novo estímulo é aplicado ao processo civilizador (ELIAS, 1993, p. 104).

Para certificar a transformação da cortesia da sociedade cavalheirosa em civilidade da sociedade de corte e, posteriormente, em civilização, quando se espraiaram os comportamentos autocontrolados, sob a sociedade burguesa, a outras nações e a classes sociais subjacentes, todas com configuração de maiores concorrência, interdependência, divisão do trabalho, de funções, especialização e a generalizar a demanda pela compulsão à contenção das pulsões e a interiorização das coerções externas, Elias elenca uma miríade de fenômenos que, a longo prazo, mostra o advento de um superego a reprimir automaticamente condutas 
outrora permitidas: o avanço do patamar da vergonha, do embaraço e da repugnância até atingir o automatismo que se observou na Modernidade expressou tamanha transformação da "estrutura da personalidade social" (ELIAS, 1993, p. 242) que somente pode ter sido explicado em uma figuração na qual se despertou sensações específicas entre pessoas hierarquizadas e reunidas como inferiores e superiores e que estavam cônscias destas relações para calcularem suas ações a fim de eximirem-se de constrangimentos; os novos hábitos à mesa que inclinaram as pessoas a evitarem comer com as mãos, que deslocaram o trinchar da carne para o fundo da cena social, que circunscreveram o uso da faca e que lançaram mão de toda sorte de utensílios e de condutas até que tivessem tornado a alimentação um "ritual diário" (ELIAS, 2011, p. 109); a transformação no hábito de assoar, que proibiu o uso das mãos e exigiu o lenço; os hábitos de quarto privatizaram o sono e o quarto, isolaram as pessoas, diminuíram os costumes dos jovens da mesma família em dividir a cama, introduziram o uso de acessórios como a camisola e o pijama para combater a nudez, esconderam o banho das demais pessoas; os hábitos de relacionamento entre os sexos aumentaram a vergonha diante das relações sexuais, bem como a distância psicológica entre adultos e crianças, impuseram maior reserva a prostíbulos até deslocá-los para o fundo da cena social, majoraram o constrangimento com relações extraconjugais, aumentaram a importância do papel social da mulher, adquiriram-se recato e autocontrole de tal forma compulsivos que se possibilitou o uso de trajes esportivos e roupas que permitiram a exposição e a liberdade do corpo, confinaram a sexualidade ao enclave particular; os hábitos de agressividade foram coagidos pela configuração de maior interdependência e de um poder 
central que deslocaram-nos para o âmbito dos sonhos e das patologias, ademais, houve refinamento da violência socialmente permitida - lutas esportivas - mediante normatizações e severamente restrita com a psicogênese do autocontrole; os hábitos diante de idosos e moribundos os isolaram, hospitalizaram-nos e trataram-nos burocrática e tecnicamente à medida que a expectativa de vida aumentou e que as pessoas tornaram-se menos expostas à morte, menos sábias em como lidar com a situação, perderam a antiga espontaneidade de outros tempos e esconderam os doentes e os mortos nos "bastidores" (ELIAS, 2001b, p. 19) mediante a assepsia clínica, o tabu e o embaraço; os hábitos de contagem do tempo das sociedades modernas, industriais, urbanizadas, com estados centralizados, amplas cadeias de interdependência e integração organizacional demandaram o cálculo de idades, anos, meses, semanas, dias, horas, minutos e segundos de maneira precisa, necessitaram do calendário, do relógio e de toda sorte de sinalização para se situar de maneira exata, cumprir horários, tornar os indivíduos atentos $\mathrm{e}$ subservientes a agendas pré-estabelecidas que os coagem ["pressão relativamente discreta, comedida, uniforme e desprovida de violência" (ELIAS, 1998b, p. 22)] e que prescindem da autodisciplina (pontualidade como virtude) e fetichizaram e substancializaram "o tempo" como se ele fosse independente da dimensão social; os hábitos esportivos modernos, notadamente os ingleses, a partir do século XVIII, abrandaram a violência das práticas anteriores, foram correlatos a formas societárias mais pacíficas de solução de conflitos (disputas políticas entre membros de um mesmo grupo de proprietários - não a oposição entre classes urbana e rural, tal como na França e na Alemanha - e parlamentarização) e à prática de 
apostas que demandaram alto nível de organização e eliminação de ambiguidades, por isso, as modalidades constituíram-se de regras (escritas, detalhadas, fiscalizadas por árbitros e com duração cronometrada da competição) a sublimarem as ações e a tolerarem tensões, de exclusão de condutas que pudessem machucar seriamente os competidores, de equipamentos de proteção, de autocontrole, de sentimento de culpa e de vergonha nos atletas, fenômenos que, em conjunto, denotaram a “afinidade" (ELIAS; DUNNING, 1992, p. 64) entre parlamentarização, monopólio da violência física pelo Estado-nação e desportivização - a prática esportiva regulamentada e profissionalizada foi expoente do "avanço da civilização" (ELIAS; DUNNING, 1992, p. 43), "parte integrante da pacificação levada a cabo pelas classes médias mais altas inglesas" (ELIAS; DUNNING, 1992, p. 55) e modo de distinção destas classes que, em seguida, espraiou as modalidades em outras regiões e classes sociais e permitiu a vazão das tensões reprimidas nas atividades sedentárias e monótonas, o despertar da catarse em situações que dispensavam perigo real, a "excitação agradável" (ELIAS; DUNNING, 1992, p. 151) pautada por regras detalhadas.

O processo civilizador evidencia a imbricação entre sociogênese e psicogênese: a revolução copernicana operada por Elias desloca a análise da canônica antinomia entre "sociedade" e "indivíduo" uma "ratoeira intelectual" (ELIAS, 2014, p. 128) orientada pelo sociologismo ou pelo atomismo - e se fundamenta na relação e no processo, ambos inteligíveis apenas caso a moderação dos impulsos articular-se com a emergência do Estado nacional monopolizador da violência física, burocrático, profissionalizado, com a urbanização, com o 
aprofundamento da divisão do trabalho e das funções a exigir das pessoas que "deixem fenecer sua verdadeira natureza" (ELIAS, 1994, p. 33), com o aumento da interdependência que incute no próprio indivíduo os valores da sociedade, interdita-o do isolamento e convoca-o a buscar o sentido de sua vida de acordo com o locus que ocupa na rede de relações. Paradoxalmente, de um lado, a interdependência pode ser uma propensão à individualidade, como Durkheim havia argumentado (ESTEVES, 2018, p. 156), à medida que entrega aos cidadãos a responsabilidade sobre suas escolhas e os educa à aquisição de uma visão do longo prazo que os inclinam a escolherem algumas oportunidades em detrimento de outras, de outro, torna cada indivíduo mais dependente dos demais, disposto em uma rede, entrelaçado e sem muita autonomia sob unidades de sobrevivência gigantescas em termos econômicos, militares, políticos, linguísticos e culturais, alcançando, assim, um "efeito de contraindividualidade" (HENRY, 2010, p. 159). O indivíduo é autorregulado e regula, é "moeda e matriz" (ELIAS, 1994, p. 52): a acepção de Elias impede tomar a individualidade (1) como criada a partir de um "ponto zero" (ELIAS, 1994, p. 56) e impenetrável às regras sociais, (2) a partir da "ideologia burguesa" (ELIAS, 2001c, p. 150) que supõe autonomia absoluta de escolhas a serem feitas por átomos pretensamente independentes em relação aos demais.

Com efeito, a perspectiva eliasiana percebe a moldagem social da estrutura psíquica dos indivíduos e os nexos com a economia (demografia, divisão do trabalho e de funções, monetarismo), a política (órgãos centrais burocratizados e monopolizadores da violência) e o domínio da natureza (indivíduos a sublimarem suas próprias pulsões): 
O controle da natureza, o controle social e o autocontrole compõem uma espécie de anel concatenado: formam um triângulo de funções interligadas que pode servir de padrão básico para a observação das questões humanas. Um lado não pode desenvolver-se sem os outros; o alcance e a forma de um dependem dos dos outros; e, quando um deles fracassa, mais cedo ou mais tarde os outros o acompanham (ELIAS, 1994, p. 116).

Este habitus formado social, relacional e processualmente, une todas as dimensões da vida e, para ser devidamente interpretado, demanda uma métrica de "universais sociológicos" constituídos como "universais de processos" (ELIAS, 1998a, p. 30): em lugar da substantivação, o movimento; do uso da linguagem das ciências naturais e das línguas europeias acostumadas a separarem o substantivo do verbo e o sujeito do predicado, um vocabulário emancipado e que respeite a interpenetração dos elementos; de replicar a divisão do trabalho acadêmico, respeitar as características dos objetos; de tomar as ações sociais como atomizadas e autonomizadas absolutamente, tratá-las dentre o "jogo" (ELIAS, 2014, p. 104) que as coage, abordá-las em respeito à interdependência em que se encontram e que exige que a Sociologia se caracterize como ciência que não reduza estas questões à simplicidade da ideia dualista e mecânica de causa e efeito para, assim, não menosprezar as interpenetrações; de repetir o vício cristão e burguês de buscar o ponto de partida de cada fenômeno, ocupar-se com o processo; da teleologia que projeta o ego em fenômenos de larga escala, a consideração do múltiplo e do heterogêneo; de limitar a pesquisa a períodos de curto prazo, considerar o longo prazo que alcança a percepção do processo; de contrapor micro e macrossociologia, diluir suas 
fronteiras para notar os nexos entre estruturas sociais e de personalidade; da antinomia indivíduo e sociedade, a consideração de que não há um sem o outro.

À guisa de considerações finais, os resultados da presente pesquisa apontam para Hobbes como Autor que pensa o Estado como predecessor da divisão do trabalho e da ordem social (a indústria, as artes, a propriedade e, no limite, a própria sociedade): pela política, estatuem-se condições de possibilidade para alavancar a segurança e o conforto ensejados pelo progresso que a divisão do trabalho (e outras instituições) oferta a indivíduos contratantes e artífices da sociedade civil; protege-se a vida de cada um pelos grilhões que o Leviatã impõe à liberdade absoluta e ao gládio individual.

Acerca de Norbert Elias, a divisão do trabalho não antecede nem sucede o processo civilizador, a sociedade e o indivíduo: ela foi um dos componentes - ao mesmo tempo, expoente e veículo - a contribuir com a sociogênese e a psicogênese da edificação do Ocidente Moderno e da metamorfose cortesia-civilidade-civilização. Em lugar do esprit de géometrie, a Sociologia de processos expôs a interpenetração entre os costumes e a política para evitar o sociologismo e o atomismo, assim, edificou saberes satisfatórios para relacionar hábitos à mesa e centralização política, o avanço do patamar da vergonha, do embaraço e da repugnância e a interdependência entre classes sociais, os novos hábitos de contenção da agressividade e a monopolização da força física por parte do Estado, a desportivização e a parlamentarização... 
Contudo, a despeito de metodologias tão diferentes (individualismo metodológico e Sociologia de processos) e de terem escrito suas teorias em momentos diferentes (mercantilismo e capitalismo monopolista), há pontos de contato entre as duas abordagens e que ilustram a maneira burguesa de entrelaçar a apologia da ordem e a divisão do trabalho. Algo que, é verdade, não foi realizado apenas por Hobbes e Elias. Para, laconicamente, registrar mais dois casos, Adam Smith havia considerado que a divisão do trabalho contribuíra com a produção e distribuição de riquezas, entrelaçando divisão do trabalho e apologia da ordem por razões econômicas; Durkheim, posteriormente, argumentara que a divisão do trabalho ajudara a produzir uma forma específica de solidariedade social, a orgânica, e entrelaçou, assim, divisão do trabalho e apologia da ordem por razões morais (ESTEVES, 2018, p. 156). Acerca dos autores em pauta neste artigo, Hobbes argumentou que a divisão do trabalho propicia conforto à medida que os indivíduos-cogumelo têm a garantia do Leviatã para produzir, com os próprios esforços, aquilo que não lhes será subtraído à medida que a observação das leis de natureza ocorrerá entre todos que estão sob o olhar constante do soberano, entrelaçando, com efeito, divisão do trabalho e apologia da ordem por razões materiais e diagnosticando que vale a pena que cada indivíduo suspenda suas escolhas absolutas - já se observava em Hobbes um "ideal de civilização" (STRAUSS, 2011, p. 21); Elias, séculos depois, expôs a divisão do trabalho e das funções, além da emergência do Estado-nação como monopolizador da violência e da arrecadação de impostos, em relação com os costumes e com o avanço do processo civilizador - todos estes elementos mostraram-se em compasso com estruturas de 
personalidade que formaram indivíduos a se autocontrolarem compulsivamente, entrelaçando, dessa forma, divisão do trabalho e apologia da ordem em virtude da coerção externa ter sido internalizada e encetar a possibilidade de uma civilização mais pacificada do que foi outrora, diagnosticando, outrossim, que não é possível realizar escolhas absolutas.

Sublinham-se dois pontos de contato entre Hobbes e Elias, expostos nos próximos dois parágrafos, que denotam o compromisso dos autores com a ordem social de seus tempos.

O primeiro Autor não vislumbra a violência do Estado como unicamente negativa à medida que contribui para alcançar vínculos societários pacificados; o segundo nota que o monopólio da força por parte do Estado coloca a violência física em latência entre os indivíduos e possibilita, assim, relações sociais intermediadas por outras maneiras de resoluções de conflitos - os dois autores participam de uma tradição que não pinta a violência, apenas, de maneira sombria (NEIBURG, 1999, p. 41). Hobbes esforça-se, constantemente, para evitar o retorno da guerra de todos contra todos: não é legítimo nada que rivalize com o soberano e que enseje faccionismo, estado dentro do Estado; por isso, o Leviatã suspende o gládio individual, protege a todos tanto dos estrangeiros como de si mesmos, açula o medo nos indivíduos-cogumelo, a fim de que se submetam à ordem e a respeitem, acresce o incentivo à esperança, para que se esforcem e alcancem seus anseios com a ajuda de outras instituições também resultantes da garantia de segurança (dentre elas, a divisão do trabalho); a sociedade e a ordem somente existem sob o Estado monopolizador da força e da arrecadação de impostos. Elias considera 
como "efeito descivilizador" (ELIAS, 1998a, p. 21) a recorrência à violência para opor-se à ordem estabelecida à medida que dissuade os indivíduos a se autocontrolarem, origina surtos de regressão e de barbárie, dentro do processo civilizador, e opera como pendor à continuidade de ações ilegítimas de outsiders contra estabelecidos e vice-versa - este foi o diagnóstico do Autor que o colocou em posição contrária aos movimentos estudantis e extraparlamentares da Alemanha da década de 1960, uma vez que eles recusaram os procedimentos da democracia representativa e retiraram a violência da latência (ESTEVES, 2019, p. 34). É verdade que Hobbes pensou o Estado de um modo (para ele, a melhor forma era a monarquia) e Elias de outro (a democracia representativa contribuía para represar a violência e mantê-la em latência); mas também o é que houve juízos apologéticos do "Leviatã" ou do Estado-nação como "unidade de sobrevivência" - ao monopolizar a violência, circunscrevê-la a especialistas e ao fundo da cena social, ele tornaria a vida possível e mais pacificada, substituindo os duelos, as vinganças e as guerras por outros expedientes.

Hobbes não pensa que a ação do Leviatã contra a parcialidade, o orgulho e a vingança entre os indivíduos, subtraia-os da liberdade; para ele, trata-se da construção do império do "bem comum" (HOBBES, 1974, p. 109) da lei civil e do impedimento de uma forma de liberdade, a saber, aquela "liberdade absoluta" (HOBBES, 1992, p. 263) peculiar ao estado de natureza e que levou à guerra de todos contra todos em virtude de todos terem direito a tudo; a fim de evitar a situação escatológica, os indivíduoscogumelo, por contrato, estabeleceram a sociedade e outra forma de liberdade (civil), a que, voluntariamente, joga objetos ao mar para que o 
barco não afunde, que constrói uma vida mais segura e confortável; portanto, o indivíduo continua movimentando-se - liberdade é movimento ${ }^{12}$ - para arvorar a "mútua relação entre proteção e obediência" (HOBBES, 1974, p. 414), para decidir abrir mão do gládio individual, consentir e se submeter, transformar-se em súdito, deixar de obedecer caso o soberano não lhe assegure a vida. Ao contrário de Hobbes, Elias não pensa as escolhas a serem feitas pelo indivíduo pelo alvitre do homo clausus: o sociólogo argumenta que elas precisam ser consideradas a partir da relação entre as pessoas, pois elas moldam e são moldadas umas às outras, estão dispostas em interdependência, em posições hierárquicas que impedem escolhas absolutas, submetidas a um processo de socialização que impõe modelos de vida adulta às gerações que estão a se desinfantilizar e que nelas interioriza os valores vigentes, inseridas em um processo civilizador que ocorre sob a sociogênese e a psicogênese de fenômenos como a divisão do trabalho e das funções, a centralização política em Estados-nacionais e a formação de novos hábitos. Estes

12 “A liberdade (...) nada mais é que ausência dos impedimentos e obstáculos ao movimento; portanto, a água represada num vaso não está em liberdade, porque o vaso a impede de escoar; quebrado o vaso, ela é libertada. E todo homem tem maior ou menor liberdade, conforme tenha mais espaço ou menos para si: como quem está numa ampla prisão é mais livre do que numa prisão apertada. E um homem pode ser livre para um rumo e contudo não o ser para outro, assim como o viajante está aprisionado deste e daquele lado por cercas vivas ou muros de pedras (para que não estrague as vinhas ou cereal), adjacentes à estrada. E estas espécies de impedimento são externas e absolutas. Em tal sentido, são livres todos os servos e súditos que não se encontram agrilhoados e aprisionados" (HOBBES, 1992, p. 171). 
fenômenos deixam um "campo muito restrito e unilateral para as faculdades e inclinações do indivíduo" (ELIAS, 1994, p. 33), compõem uma configuração que impede a efetividade daquela autonomia suposta pelo atomismo burguês, que obstaculiza a "verdadeira natureza" e a “'verdade interior"” (ELIAS, 1994, p. 33, entre aspas no original), que "aumenta a impotência do indivíduo em relação ao que acontece no nível superior da humanidade" (ELIAS, 1994, p. 138) e que majora a dependência entre pessoas que se transformaram em especialistas em uma sociedade de grande avanço técnico e científico - há espaços para decisões individuais, mas circunscritas a limites como a posição social, a interdependência, a estrutura de poder e de tensões, todos a edificarem, no próprio indivíduo, autocontrole. Foi o que aconteceu com Mozart: seu "dom especial" estava relacionado ao "destino social" (ELIAS, 1995, p. 54) que contou com uma educação rigidamente disciplinada, controlada pelo pai do músico; à luta de classes entre cortesãos e burgueses, durante a segunda metade do século XVIII, em Salzburgo, que impunha a necessidade dos músicos, para sobreviverem, alcançar um lugar nas redes institucionais da corte e orientarem-se pelo padrão de gosto dos senhores estabelecidos. Mozart não quis se limitar a ser reprodutor da música de corte e promoveu alterações no material musical que contrariavam o status quo estético da aristocracia de Salzburgo: introduziu um número expressivo de notas, privilegiou os instrumentistas em lugar dos cantores, estabeleceu autonomia da música em relação à poesia, do compositor que queria deixar-se guiar por sua própria imaginação - em relação à nobreza. Assim, Mozart demitiu-se da corte para trabalhar de maneira livre das imposições da nobreza (lecionando, organizando e vendendo concertos 
para um público anônimo; mas sem sucesso, uma vez que o mercado musical propriamente burguês, em Salzburgo, ainda era muito incipiente). Observa-se, portanto, que o talento de Mozart estava relacionado à configuração social de seu tempo: para se efetivar, não apenas o desejo bastou para que a liberdade em relação ao gosto principesco ocorresse, o artista burguês estava diante de uma formação ainda aristocrática e as tensões do músico tanto em relação com seu pai, como com toda a corte, tornaram-se inevitáveis - tensões observáveis no próprio material musical.

Se Hobbes fez apologia da ordem ao condenar a "liberdade absoluta”, Elias mostrou que as escolhas absolutamente autônomas sequer são possíveis: do mercantilismo à era dos monopólios, a divisão do trabalho e das funções, o crescimento da interdependência e da centralização política das "unidades de sobrevivência" foram expostos em um "processo civilizador", afinados a hábitos pacificados e pacificadores, que dispõem os indivíduos em uma ordem social caracterizada como uma rede menos violenta e cujo esteio o Autor deixa transparecer.

\section{Referências}

BLOCH, E. O princípio esperança vol. 2. Trad. de W. Fuchs, Rio de Janeiro: EDUERJ; Contraponto, 2006.

BOBBIO, N. Thomas Hobbes. Trad. de C. N. Coutinho, Rio de Janeiro: Campus, 1991.

CHARTIER, R. "Formação social e economia psíquica: a sociedade de corte no processo civilizador" In: ELIAS, N. A sociedade de corte: 
investigação sobre a sociologia da realeza e da aristocracia de corte. Trad. de P. Süssekind, Rio de Janeiro: Zahar, 2001.

ELIAS, N. O processo civilizador volume I: uma história dos costumes. $2^{\circ}$ ed. Trad. de R. Jungmann, Rio de Janeiro: Jorge Zahar, 2011.

ELIAS, N. O processo civilizador volume 2: formação do Estado e Civilização. Trad. de R. Jungmann, Rio de Janeiro: Jorge Zahar, 1993.

ELIAS, N. A sociedade de corte: investigação sobre a sociologia da realeza e da aristocracia de corte. Trad. de P. Süssekind, Rio de Janeiro: Zahar, 2001a.

ELIAS, N. A sociedade dos indivíduos. Trad. de V. Ribeiro, Rio de Janeiro: Jorge Zahar, 1994.

ELIAS, N. Os alemães: a luta pelo poder e a evolução do habitus nos séculos XIX e XX. Trad. de A. Cabral, Rio de Janeiro: Jorge Zahar, 1997.

ELIAS, N. Introdução à sociologia. $3^{\circ}$ ed. Trad. de M. L. R. Ferreira, Lisboa: Edições 70, 2014.

ELIAS, N. Envolvimento e alienação. Trad. de A. de Sá, Rio de Janeiro: Bertrand Brasil, 1998a.

ELIAS, N. A condição humana. Trad. de M. Loureiro, Lisboa; Rio de Janeiro: Difel; Bertrand Brasil, 1991.

ELIAS, N. Teoria simbólica. Trad. de P. Valverde, Oeiras: Celta, 1994.

ELIAS, N. A solidão dos moribundos. Trad. de P. Dentzien, Rio de Janeiro: Jorge Zahar, 2001b.

ELIAS, N. Sobre o tempo. Trad. de V. Ribeiro, Rio de Janeiro: Jorge Zahar, 1998b.

ELIAS, N. Mozart, Sociologia de um gênio. Trad. de S. G. de Paula, Rio de Janeiro: Jorge Zahar, 1995. 
ELIAS, N. A peregrinação de Watteau à Ilha do Amor. Trad. de A. C. Santos, Rio de Janeiro: Jorge Zahar, 2005.

ELIAS, N. Escritos \& ensaios 1: Estado, processo, opinião pública. Trad. de S. Benevides, A. C. dos Santos, J. C. Pijnappel, Rio de Janeiro: Jorge Zahar, 2006.

ELIAS, N. Norbert Elias por ele mesmo. Trad. de A. T., Rio de Janeiro: Jorge Zahar, 2001c.

ELIAS, N.; SCOTSON, J. Os estabelecidos e os outsiders: Sociologia das relações de poder a partir de uma pequena comunidade. Trad. de V. Ribeiro, Rio Janeiro: Zahar, 2000.

ELIAS, N.; DUNNING, E. A busca da excitação. Trad. de M. M. A. e Silva, Lisboa: Difel, 1992.

ESTEVES, A. A. "Catálise para mudança social qualitativa ou efeito descivilizador? O estatuto dos movimentos estudantil e extraparlamentar em Herbert Marcuse e Norbert Elias" In: Kínesis. Marília (SP): vol. 11, ${ }^{\circ}$ 28, jan.- jun., 2019, pp. 15-37. https://doi.org/10.36311/19848900.2019.v11.n28.03.p15

ESTEVES, A. A. "Apologia da ordem e divisão do trabalho em Adam Smith e Émile Durkheim” In: Argumentos. Fortaleza: ano 10, $\mathrm{n}^{\circ} 19$, jan.jun., 2018, pp. 151-160.

GARRIGOU, A.; LACROIX, B (Orgs). Norbert Elias: a política e a história. São Paulo: Perspectiva, 2010.

HEINICH, N. A Sociologia de Norbert Elias. Trad. de V. Ribeiro, Bauru (SP): EDUSC, 2001.

HENRY, C. "Elementos para uma teoria da individualização. Quando o criado Mozart se achava um livre artista" In: GARRIGOU, A.; LACROIX, 
B (Orgs). Norbert Elias: a política e a história. São Paulo: Perspectiva, 2010.

HOBBES, T. Os elementos da lei natural e política: tratado da natureza humana, tratado do corpo político. Trad. de F. D. Andrade, São Paulo: Ícone, 2002

HOBBES, T. Do cidadão. Trad. de R. J. Ribeiro, São Paulo: Martins Fontes, 1992.

HOBBES, T. Leviatã ou matéria, forma e poder de um Estado eclesiástico e civil. Trad. de J. P. Monteiro e M. B. N. da Silva, São Paulo: Abril, 1974.

HOBBES, T. Elementos da Filosofia: sobre o corpo. Trad. de M. de M. M. Dantas, São Paulo: Ícone, 2012.

HOBBES, T. Behemoth ou o longo parlamento. Trad. de E. Ostrensky, Belo Horizonte: UFMG, 2001.

HOBBES, T. Diálogo entre um filósofo e um jurista. Trad. de R. Fiker, São Paulo: Edipro, 2015.

IANNI, O. "Variações sobre arte e ciência" In: Tempo social. São Paulo: USP, vol. 16, $\mathrm{n}^{\circ} \quad 1, \quad 2004$. https://doi.org/10.1590/S0103$\underline{20702004000100001}$

LIMONGI, M. I. "Hobbes: o homem lobo do homem, o homem Deus do homem” In: SGANZERLA, A.; VALVERDE, A. J. R.; FALABRETTI, E. (Orgs.) Natureza humana em movimento: ensaios de antropologia filosófica. São Paulo: Paulus, 2012.

LIMONGI, M. I. "Hobbes: o poder de estado entre a força e o direito" In: SGANZERLA, A.; VALVERDE, A. J. R.; FALABRETTI, E (Orgs). $O$ pensamento político em movimento: ensaios de Filosofia Política vol. 1. Curitiba: PUCPRess, 2016. 
MARX, K.; ENGELS, F. A ideologia alemã: crítica da mais recente filosofia alemã em seus representantes Feuerbach, B. Bauer e Stiner, e do socialismo alemão em seus diferentes profetas (1845-1846). Trad. de R. Enderle, N. Schneider, L. C. Martorano, São Paulo: Bointempo, 2007.

NEIBURG, F. "O naciocentrismo das Ciências Sociais e as formas de conceituar a violência política e os processos de politização da vida social" In: WAIZBORT, L. Dossiê Norbert Elias. São Paulo: Edusp, 1999.

RIBEIRO, R. J. Ao leitor sem medo: Hobbes escrevendo contra o seu tempo. $2^{\circ}$ ed. Belo Horizonte: UFMG, 1999.

RIBEIRO, R. J. A marca do Leviatã: linguagem e poder em Hobbes. $2^{\circ}$ ed. Cotia (SP): Ateliê, 2003.

RIBEIRO, R. J. "Hobbes: o medo e a esperança" In: WEFFORT, F. C. Os clássicos da política: 1. São Paulo: Ática, 1989.

RIBEIRO, R. J. “Apresentação” In: HOBBES, T. Do cidadão. Trad. de R. J. Ribeiro, São Paulo: Martins Fontes, 1992.

RIBEIRO, R. J. "A mídia do dezessete" In: HOBBES, T. Behemoth ou o longo parlamento. Trad. de E. Ostrensky, Belo Horizonte: UFMG, 2001.

SKINNER, Q. Razão e retórica na filosofia de Hobbes. Trad. de V. Ribeiro, São Paulo: UNESP, 1999.

SKINNER, Q. Hobbes e a liberdade republicana. Trad. de M. Florenzano, São Paulo: Unesp, 2010.

STRAUSS, L. La filosofía política de Hobbes: su fundamento y su génesis. Trad. de S. Carozzi, Buenos Aires: Fondo de Cultura Econômica, 2011.

TAYLOR, C. As fontes do self: a construção da identidade moderna. $3^{\circ}$ ed. Trad. de A. U. Sobral e D. A. Azevedo, São Paulo: Loyola, 2011.

WAIZBORT, L. (Org.) Dossiê Norbert Elias. São Paulo: Edusp, 1999. 
Divisão do trabalho e apologia da ordem em Thomas Hobbes e Norbert Elias

Data de registro: 09/08/2019

Data de aceite: $26 / 05 / 2020$ 